\title{
A compilation of research working groups on drug utilisation across Europe
}

\author{
Mònica Sabaté ${ }^{1,2,3}$, Juan Fernando Pacheco ${ }^{1,2,3}$, Elena Ballarín ${ }^{1,2,3}$, Pili Ferrer ${ }^{1}$, Hans Petri ${ }^{4}$, Joerg Hasford ${ }^{5}$, \\ Marieke Wilma Schoonen ${ }^{6}$, Marietta Rottenkolber ${ }^{5}$, Joan Fortuny ${ }^{7}$, Joan-Ramon Laporte ${ }^{1,2,3}$, Luisa Ibáñez $z^{1,2,3^{*}}$ \\ and On behalf of the PROTECT Work Package 2
}

\begin{abstract}
Background: The assessment of the benefit-risk of medicines needs careful consideration concerning their patterns of utilization. Systems for the monitoring of medicines consumption have been established in many European countries, and several international groups have identified and described them. No other compilation of European working groups has been published.

As part of the PROTECT project, as a first step in searching for European data sources on the consumption of five selected groups of medicines, we aimed to identify and describe the main characteristics of the existing collaborative European working groups.
\end{abstract}

Findings: Google and bibliographic searches (PubMed) of articles containing information on databases and other sources of drug consumption data were conducted. For each working group the main characteristics were recorded. Nineteen selected groups were identified, focusing on: a) general drug utilisation (DU) research (EuroDURG, CNC, ISPE'S SIG-DUR, EURO-MED-STAT, PIPERSKA Group, NorPEN, ENCePP, DURQUIM), b) specific DU research: b.1) antimicrobial drugs (ARPAC, ESAC, ARPEC, ESGAP, HAPPY AUDIT), b.2) cardiovascular disease (ARITMO, EUROASPIRE), b.3) paediatrics (TEDDY), and b.4) mental health/central nervous system effects (ESEMeD, DRUID, TUPP/EUPoMMe). Information on their aims, methods and activities is presented.

Conclusions: We assembled and updated information on European working groups in DU research and in the utilisation of five selected groups of drugs for the PROTECT project. This information should be useful for academic researchers, regulatory and health authorities, and pharmaceutical companies conducting and interpreting post-authorisation and safety studies. European health authorities should encourage national research and collaborations in this important field for public health.

Keywords: Pharmacoepidemiology, Pharmacovigilance, European network, Drug utilisation, Drug consumption, National databases, Review

\section{Findings}

The assessment of the benefit-risk of medicines needs careful consideration concerning their patterns of utilization.

Systems for the monitoring of medicines consumption and assessing their benefit-risk have been established in many European countries. Several international groups have identified and described those systems.

\footnotetext{
* Correspondence: li@icf.uab.es

${ }^{1}$ Fundació Institut Català de Farmacologia, Pg. Valld'Hebron 119-129, Barcelona 08035, Spain

${ }^{2}$ Servei de Farmacologia Clínica, Hospital Universitari Vall d'Hebron, Barcelona, Spain

Full list of author information is available at the end of the article
}

To identify and describe the main characteristics of the existing collaborative European working groups, we conducted a Google and bibliographic searches (PubMed) of articles containing information on databases and other sources of drug consumption data of medicines.

Nineteen selected groups were identified, focusing on: a) general drug utilisation (DU) research (EuroDURG, CNC, ISPE'S SIG-DUR, EURO-MED-STAT, PIPERSKA Group, NorPEN, ENCePP, DURQUIM), b) specific DU research: b.1) antimicrobial drugs (ARPAC, ESAC, ARPEC, ESGAP, HAPPY AUDIT), b.2) cardiovascular disease 
(ARITMO, EUROASPIRE), b.3) paediatrics (TEDDY), and b.4) mental health/central nervous system effects (ESEMeD, DRUID, TUPP/EUPoMMe). Information on their aims, methods and activities is presented.

\section{Introduction}

Drug utilisation research is defined by the World Health Organization (WHO) as "the development, regulation, marketing, distribution, prescription, dispensing and use of medicines within a society, with special emphasis on the medical, social and economic consequences" [1]. A broad definition should also include the qualitative studies for assessing the appropriateness of drug utilisation and the intervention studies [2]. Drug utilisation research plays a key role in understanding the use of medicines and evaluating the effect of interventions (such as policy changes, reimbursement policy and regulatory decisions) on drug use, thereby ameliorating the quality of care and improving public health.

The Pharmacoepidemiological Research on Outcomes of Therapeutics by a European ConsorTium (PROTECT) study is a collaborative European project which aims to enhance the monitoring of the safety of medicinal products [3]. One of the specific objectives of PROTECT is to build and update an inventory of data sources on the consumption of medicines in the European Union as a tool to estimate the public health impact of several adverse drug events.

Efforts to collect information about the use of medicines in European countries date from the seventies. There is a wide international variability in drug utilisation documented in a WHO-Regional Office for Europe sponsored meeting [4]. In addition, information about the overall use of medicines across European countries is of interest to estimate the public health impact of adverse effects associated with the use of medicines $[5,6]$. As a first step in searching for European data sources for medicines consumption, we aimed to describe and update the main characteristics of the collaborative international European working groups, networks, and research projects related to drug utilisation.

\section{Methods}

\section{Search strategy:}

1. Internet search. The goal was to find institutions, networks and research projects related to drug utilisation in Europe in general and those focused on six groups of drugs, namely: 1 ) inhaled beta- 2 agonists; 2) antibiotics; 3) antidepressants 4) benzodiazepines; 5) anticonvulsants, and 6) calcium channel blockers [3].

2. Bibliographic search: (1990-2010) in PubMed and SIETES (Sistema de Información Esencial en Terapéutica y Salud (http://www.sietes.org), an electronic drug information system in Spanish). Keywords: "databases", "drug utilization", "drug utilization research", "Europe", "international cooperation", "international group", "national databases", "network", "pharmacoepidemiology" and "working group".

\section{Group selection criteria}

Working groups were included if they were European groups, focused on drug utilisation and/or if they were involved in research on the medicines of interest for the PROTECT project. This selection was done according to pre-defined criteria such as regulatory and public health impact, and the potential to investigate a broad range of methodological issues [7].

Groups studying a single condition and/or those focusing only on drugs of no interest for the PROTECT project, or based on a single European country, or not active at the time of search, were excluded.

\section{Data abstraction}

The characteristics of each working group were collected from their websites or from methods and acknowledgement sections in published papers.

These data were analysed in a descriptive manner.

\section{Results}

Twenty-four European working groups on drug utilisation were identified, nineteen of which fulfilled our eligibility criteria. Additional information on excluded groups can be found on (http://www.icf.uab.es/EuropeanWG).

The characteristics of the working groups are described in the Additional file 1: Table S1. Eight groups focused on promoting general drug utilisation research and eleven focused on specific fields.

\section{Discussion}

As far as we know, no other compilation of European collaborative working groups and their sources of data on medicines utilisation have been published.

Nineteen European groups were selected: eight groups were interested in general drug utilisation research or pharmacoepidemiology, with the common objective of compiling information on data sources, either at a European level (e.g., ENCePP in Europe) or at a more restricted geographical level (e.g., NorPen in the Nordic countries). The remaining eleven groups focused their research on specific fields, mainly antimicrobials, cardiovascular conditions, paediatrics, and mental health (e.g., ESAC: antimicrobials, EUROASPIRE: cardiovascular conditions).

Among the groups focusing on general drug utilisation the EURO-MED-STAT widened the initial EuroMedicines project and developed a European database 
of licensed medicines and their prices in twenty European countries [8].

The CNC project offered a wide range of sources of medicines consumption data for eighteen countries. However, the information is not published but available on a website [9], and it is not clear whether the information has been kept updated.

EnCePP, led by the European Medicines Agency (EMA), was established to strengthen the postmarketing monitoring of medicines. Its website contains a voluntary register of the healthcare databases existing in all European countries including those monitoring drug consumption.

Our search identified several European working groups collecting information on the utilisation of the selected groups of medicine even though their main objective goes beyond the collection of drug consumption data.

As expected, we found wide heterogeneity in the nature and quality of the drug utilisation data among the groups. The main factors determining their heterogeneity were: a) variability in the population coverage, and in the number of countries involved in each working group; b) differences in medicines coding systems, and c) source of the drug utilisation data (e.g., questionnaires to individuals, samples or registers of prescribed/dispensed medicines). In addition, none of the groups, except ESAC, has tried to validate drug utilisation data [10].

Inhaled beta- 2 agonists and anticonvulsants did not appear in our search in relation to medicines consumption. This could be explained by the fact that the groups working in those areas concentrate more on risk factors associated with diseases rather than on exposure to medicines.

Most of the initiatives in this field have received public funding. As a consequence a lot of good initiatives and efforts could have been lost if this funding had ended. Funding is decisive in keeping these research working groups ongoing.

The general working groups contribute to the collaboration in pharmacoepidemiology and specifically in drug utilisation research studies across the European countries through improving the research in this field and the quality of health care management. For example, PIPERSKA contributes to enhancing the rational use of drugs in different countries and the Nordic network NorPEN facilitates and promotes safer and more efficient medicines in a public health perspective in the Nordic countries. Among its goals there is the objective to increase quality of research and methodological development within pharmacoepidemiology in the Nordic countries.

The importance and impact of the specific drug utilisation groups in the medical community stems from the collaborative research in drug utilisation and methodological innovation as well as from aspects derived from their field of interest. For instance, the groups focusing on antibiotics such as ESAC, have contributed not only to a specific field such as the use of antibiotics in Europe but to guidelines for methods in drug utilisation research (i.e, study design and comparison of drug utilisation data across different countries). The field of antimicrobial drugs has traditionally interested European researchers due to its relationship with the appearance of resistances. Those groups interested in cardiovascular diseases such as ARITMO or EUROASPIRE work on diseases with a high public health impact [11], and they have been active for a long time. Their importance also lies in their interest in adverse drug reactions and in prognostic factors for disease prevention. Other initiatives such as TEDDY focus on the paediatric population. TEDDY has the purpose of promoting the availability of safe and effective paediatric drugs to overcome the difficulties and complexity of research in this population. It continues the activities through the participation in other on-going projects (ex Global Research in Paediatrics (GRIP)). Finally the research groups focusing on mental diseases derive their importance from the high prevalence of mental diseases worldwide [12].

The strengths of our compilation are the standardised search and the categorising of the information as general and specific-related drug utilisation areas in Europe. The broad search lets us find out about the general groups on drug utilisation as well as those focusing on the selected PROTECT drugs. This paper highlights some of the benefits of international collaboration such as the possibility of sharing and transferring knowledge and the high number of participating countries involved. This international collaboration is also important for pharmacovigilance activities, to enable the regulatory institutions such as the EMA to obtain fast and reliable information for population benefit-risk assessment. It also facilitates regulatory decision-making and assessing the public health impact of the use of medicines [13]. In addition, this compilation can promote networking between researchers and contribute to multidatabase studies which are of increasing interest for drug safety issues nowadays (ie, ESAC, TEDDY, GRIP).This work has provided not only an overview of the availability of drug utilisation data for the drug-adverse event pairs included in the PROTECT project, but also an update on the methodological framework for drug utilisation studies $[10,14,15]$. Finally, the access to the information and knowledge held by the groups are described. Researchers can use this information in pharmacoepidemiological studies to improve patient's therapeutic management.

Our research has some limitations. First, some working groups could have been missed because of the difficulty in understanding some non-English language websites. Second, although we conducted a complete search, part of the results refers only to the drugs of interest for the PROTECT project. Third, the information about the data on medicines 
utilisation available for each working group has been extracted from their website or from the methods section in the published references, which is sometimes summarised. Finally, the update of the information has been difficult because the websites are not updated regularly.

\section{Conclusion}

We assembled and updated information on European working groups in drug utilisation research and in the utilisation of five selected groups of drugs for the PROTECT project. A description of the main working groups and information on their data characteristics has been provided. This information should be of value for academic researchers, regulatory authorities, health authorities and pharmaceutical companies conducting and interpreting post-authorisation and safety studies. European and member states' health authorities should encourage and support national research and European collaboration in this important field for public health.

\section{Additional file}

Additional file 1: Table S1. European working groups on general drug utilisation and on specific fields on drug utilisation.

\begin{abstract}
Abbreviations
ARITMO: Arrhythmogenic potential of drugs; ARPAC: Antibiotic resistance prevention and control; ARPEC: Antibiotic resistance and prescribing in European children; ATC: Anatomical therapeutic chemical; CNC: Cross national comparison; DDD: Defined daily dose; DG SANCO: Directorategeneral for health and consumers; DRUID: Driving under the influence of drugs, alcohol and medicines; DU: Drug utilisation; DURQUIM: Drug utilisation research quality indicator meeting; EMA: European medicines agency; ENCePP: European network of centres for pharmacoepidemiology and pharmacovigilance; ESAC: European surveillance of antimicrobial consumption; ESEMeD: European study of the epidemiology of mental disorders; ESCMID-ESGAP: European society of clinical microbiology and infectious diseases- study group for antibiotic policies; EU: European union; EUROASPIRE: European action on secondary and primary prevention by intervention to reduce events; EuroDURG: European drug utilisation research group; EURO-MED-STAT: European medicines statistics; GRIP: Global research in paediatrics; HAPPY AUDIT: Health alliance for prudent, yield, and use of antimicrobial drugs in the treatment of respiratory tract infections; ISPE'S SIG-DUR: International society of pharmacoepidemiology special interest group of drug utilisation research; NorPEN: Nordic pharmacoepidemiological network; PROTECT: The pharmacoepidemiological research on outcomes of therapeutics by a European consortium; SIETES: Sistema de información esencial en terapéutica y salud; UK: United Kingdom; TEDDY: Task force in Europe for drug development for the young; TUPP/EUPoMMe: The users perspective project; WHO-DURG: World health organization drug utilisation research group.
\end{abstract}

\section{Competing interests}

Sabaté M, Pacheco JF, Ballarín E, Ferrer P, Laporte J-R, Ibáñez L, Hasford J and Rottenkolber $\mathrm{M}$ declared that they do not have anything to disclose regarding funding or competing interests with respect to this manuscript. Petri H was employee of Roche until April 2012. Schoonen WM is an employee of Amgen Ltd. Fortuny $J$ is an employee at Novartis Pharma AG. Costs related to their part in the research were carried by the respective company as in-kind contribution under the IMI JU scheme.

\section{Authors' contributions}

MS participated in the conception and design, data collection, data analysis, interpretation of data and writing the paper. LI participated in the conception and design, interpretation of data, and writing the paper. JP participated in the data analysis, and revising it critically for important intellectual content. EB participated in the conception and design, data collection, interpretation of data, data analysis, drafting the article and revising it critically for important intellectual content. PF participated in the conception and design, data collection, interpretation of data, and drafting the article, and revising it critically for important intellectual content. All other authors participated in the conception and design, interpretation of data, and revising it critically for important intellectual content. All authors read and approved the final manuscript.

\section{Funding}

The research leading to these results was conducted as part of the PROTECT consortium (Pharmacoepidemiological Research on Outcomes of Therapeutics by a European ConsorTium) which is a public-private partnership coordinated by the European Medicines Agency. The PROTECT project has received support from the Innovative Medicines Initiative Joint Undertaking (www.imi.europa.eu) under Grant Agreement no 115004, resources of which are composed of financial contribution from the European Union's Seventh Framework Programme (FP7/2007-2013) and EFPIA companies' in kind contribution.

Yeboa S and Goh KL were employed by Amgen Ltd at the time of their contribution to conception of the study idea, design of the search strategy and the initial draft of this paper. Solari P was employed by FICF at the time of contributing to study concept and data analysis. We acknowledge Xavier Vidal and Albert Figueras for their insightful review of this manuscript. The members of Pharmacoepidemiological Research on Outcomes of Therapeutics by a European Consortium WP2 (framework for pharmacoepidemiology studies) are the following: Y. Alvarez, J. Slattery, X. Kurz, G. Candoere, J. Durand, S. Blackburn (European Medicines Agency), M. Rottenkolber, J. Hasford, A. Stueven (Ludwig-Maximilians UniversitätMúnchen), F.J. de Abajo Iglesias, E. Martin Merino, M. Gil, C. Huerta, G. Requena, B. Oliva, D. Montero (Agencia Española de Medicamentos y Productos Sanitarios), L.A. Garcia-Rodriguez, A. Ruigomez (Fundación Centro Español de Investigación Farmacoepidemiológica), P.C. Souverein, L. van Dijk, A. Afonso, M. De Groot, H. Gardarsdottir, F. Rutten, R. Van den Ham, S. Belitser, A. de Boer, R. Groenwold, A.W. Hoes, W.R. Pestman, K.C.B. Roes, A.Sanni, J. Uddin, O. Klungel, D. De Bakker, W. Pestman, K. Roes, A. Hoes, V. Abbing-Krahagopian, F. De Vries, T.P. van Staa, A.C.G. Egberts, H.G.M. Leufkens, O.H. Klungel, I. Teixidor (Utrecht University, The Netherlands), J. Parkinson (The UK General Practice Research Database), P. Helboe, J. Lyngvig, A.M. Clemensen, T.S. Engraff, U. Hesse, J. Poulsen, P.F. Rønn (Lægemiddelstyrelsen, Danish Medicines Agency), J. Logie, J. Pimenta, K. Davis, E.J. Swain (GlaxoSmithkline Research and L. Abenhaim, D. Neasham (L.A. Sante Epidemiologie Evaluation Recherche), R.F. Reynolds, N. Gatto, A. Bate, J. Richards (Pfizer), G.F. Downey, R.Brauer, M. Schoonen, A.Roddam (Amgen NV), E. Velthuis, O. Demol (Genzyme Europe), M. Miret (Merck KgaA), S. Johansson (AstraZeneca AB), P. Primatesta, R. Schlienger, J.Fortuny, E. Rivero, J. Weil, E. Plana Hortoneda (Novartis), G. Quartey, I. Tatt, J. Hannon, J. Robinson, S. Vesanen (F. Hoffman-La Roche AG), J.R. Laporte, L. Ibáñez, M. Sabaté, E. Ballarín, M. Pérez and P. Ferrer (Fundació Institut Català de Farmacologia), S. Schmiedl Witten/Herdecke University-Witten).

\section{Author details}

${ }^{1}$ Fundació Institut Català de Farmacologia, Pg. Valld'Hebron 119-129, Barcelona 08035, Spain. ${ }^{2}$ Servei de Farmacologia Clínica, Hospital Universitari Vall d'Hebron, Barcelona, Spain. ${ }^{3}$ Departament de Farmacologia, Terapèutica i Toxicologia, Universitat Autònoma de Barcelona, Pg. Vall d'Hebron 119-129, Barcelona 08035, Spain. ${ }^{4}$ Hoffmann- La Roche, 6 Falcon Way, Shire Park, Welwyn Garden City AL7 1TWLondon, UK. ${ }^{5}$ Institute for Medical Information Sciences, Biometry and Epidemiology Ludwig Maximillians Universität-München, Marchioninistr. 15, 81377 Munich, Germany. ${ }^{6}$ Center for Observational Research, Amgen, Itd., 1, Uxbridge Business Park, Sanderson Road, Uxbridge, Middlesex, UK. ${ }^{7}$ Global Clinical Epidemiology Department, Novartis Pharma AG, Gran Vía Corts Catalanes, 764, 08013 Barcelona, Spain.

Received: 30 September 2013 Accepted: 1 March 2014

Published: 13 March 2014 


\section{References}

1. WHO: The selection and use of essential medicines (Report of the WHO Expert Committee, 2005 WHO Technical Report Series 2006;933).

2. Hartzema AG, Tilson HH, Chan KH: Pharmacoepidemiology and therapeutic risk management. 1st edition. Cincinatti: Harvey Whitney Books; 2008.

3. PROTECT Project: http://www.imi-protect.eu/. Accessed September/27, 2013.

4. Dukes Me: Drug utilization studies. Methods and uses. Finland: WHO Regional Publications; 1993. European Series, №45.

5. Platt R, Madre L, Reynolds R, Tilson H: Active drug safety surveillance: a tool to improve public health. Pharmacoepidemiol Drug Saf 2008, 17:1175-1182.

6. Tannen RL, Weiner MG, Xie D: Use of primary care electronic medical record database in drug efficacy research on cardiovascular outcomes: comparison of database and randomised controlled trial findings. BMJ 2009, 27:338-b81.

7. Abbing-Karahagopian V, Kurz X, de Vries F, van Staa TP, Alvarez Y, Hesse U, Hasford J, Van Dijk L, De Abajo FJ, Weil JG, Grimaldi-Bensouda L, Egberts AC, Reynolds RF, Klungel OH: Bridging differences in outcomes of pharmacoepidemiological studies: design and first results of the protect project. Curr Clin Pharmacol Curr Clin Pharmacol 2013 [Epub ahead of print].

8. Walley T, Folino-Gallo P, Barry M, Bruzzone M, DeJoncheere K, Rosian I, Schröder H, Tilson L, Vogler S, on behalf of the EuroMedStat Group: The EuroMedStat proposals on indicators for price and utilization. Italian Journal of Public Health 2006, 3:15-21.

9. CNC Drug Utilization Results. http://www.pharmacoepi.org/eurodurg/ workgr/ Accessed September/17, 2013.

10. Vander Stichele RH, Elseviers MM, Ferech M, Blot S, Goossens H, ESAC Project Group: European surveillance of antimicrobial consumption (ESAC): data collection performance and methodological approach. Br J Clin Pharmacol 2004, 58:419-428.

11. Laslett LJ, Alagona P Jr, Clark BA 3rd, Drozda JP Jr, Saldivar F, Wilson SR, Poe C, Hart M: The worldwide environment of cardiovascular disease: prevalence, diagnosis, therapy, and policy issues: a report from the American College of Cardiology. J Am Coll Cardiol 2012, 25(25 Suppl):S1-49.

12. Whiteford HA, Degenhardt L, Rehm J, Baxter AJ, Ferrari AJ, Erskine HE, Charlson FJ, Norman RE, Flaxman AD, Johns N, Burstein R, Murray CJ, Vos T: Global burden of disease attributable to mental and substance use disorders: findings from the Global Burden of Disease Study 2010. Lancet 2013, 382:1575-86.

13. Blake KV, Prilla S, Accadebled S, Guimier M, Biscaro M, Persson I, Arlett P, Blackburn S, Fitt $\mathrm{H}$ : European medicines agency review of post-authorisation studies with implications for the European network of centres for pharmacoepidemiology and pharmacovigilance. Pharmacoepidemiol Drug Saf 2011, 20:1021-1029.

14. Almansa J, Vermunt JK, Forero CG, Vilagut G, De Graaf R, De Girolamo G, Alonso J: Measurement and description of underlying dimensions of comorbid mental disorders using factor mixture models: results of the ESEMeD project. Int I Methods Psychiatr Res 2011, 20:116-33.

15. Cooney MT, Kotseva K, Dudina A, De Backer G, Wood D, Graham I: Determinants of risk factor control in subjects with coronary heart disease: a report from the EUROASPIRE III investigators. Eur J Prev Cardiol 2013, 20:686-91.

\section{Submit your next manuscript to BioMed Central and take full advantage of:}

- Convenient online submission

- Thorough peer review

- No space constraints or color figure charges

- Immediate publication on acceptance

- Inclusion in PubMed, CAS, Scopus and Google Scholar

- Research which is freely available for redistribution 